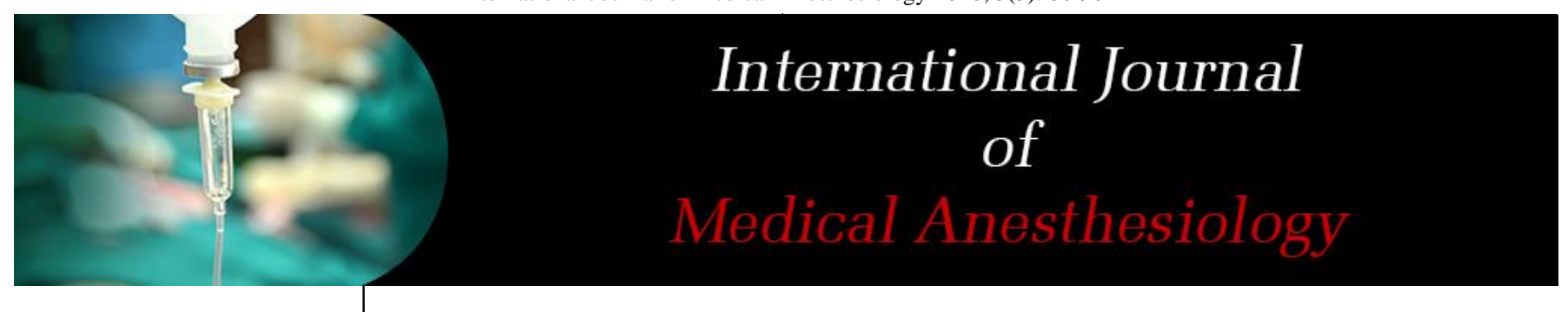

E-ISSN: 2664-3774

P-ISSN: 2664-3766

Www.anesthesiologypaper.com

IJMA 2020; 3(3): 86-90

Received: 18-05-2020

Accepted: 20-06-2020

Dr. Kavita Udaykumar Adate Professor, Department of Anaesthesia, Third floor, New Building, Navale Hospital Campus, Near Narhe Police Chowki, Narhe, Pune, Maharashtra, India

Dr. Jyoti Nagnathrao Tat Department of Anaesthesia, Third floor, New Building, Navale Hospital Campus, Near Narhe Police Chowki, Narhe, Pune, Maharashtra, India
Corresponding Author: Dr. Jyoti Nagnathrao Tat Department of Anaesthesia, Third floor, New Building, Navale Hospital Campus, Near Narhe Police Chowki, Narhe, Pune, Maharashtra, India

\section{Ultrasound guided transversus abdominals plane (TAP) block versus conventional caudal epidural block for post-operative analgesia in paediatric ilioinguinal surgeries}

\author{
Dr. Kavita Udaykumar Adate and Dr. Jyoti Nagnathrao Tat
}

DOI: $\underline{\text { https://doi.org/10.33545/26643766.2020.v3.i3b.153 }}$

\begin{abstract}
Introduction: Conventional Caudal Block $(\mathrm{CCB})$ is being used frequently for postoperative analgesia in pediatric patients. Transversus Abdominis Plane (TAP) block is now rapidly evolving peripheral nerve block technique with lower risk profile.

Aim: This study aims to evaluate analgesic efficacy and safety of USG guided TAP block and compare it with caudal block for duration and quality of postoperative analgesia.

Methodology: 60 patients of age group 01-05 years belonging to ASA I and II posted for unilateral Ilioinguinal surgery were randomized into two groups $\mathrm{C}$ and $\mathrm{T}$ of 30 each to receive either CCB with $1 \mathrm{ml} / \mathrm{kg} 0.25 \%$ bupivacaine or USG guided TAP block with $0.5 \mathrm{ml} / \mathrm{kg} 0.25 \%$ bupivacaine after induction of anesthesia. Parameters observed for 24 hours postoperatively included hemodynamic changes, postoperative duration of analgesia by CHEOPS pain score, total analgesic requirement, quality of analgesia with Parent Patient Satisfaction score, residual motor block with Modified Bromage Scale and adverse effects.

Results: TAPB is initially equivalent to $\mathrm{CCB}$ in providing post-operative pain control but would also show improved immediate post-operative pain relief and analgesic efficacy beyond the anticipated caudal duration

Conclusion: USG guided TAP block is safe and effective method with good Parent Patient satisfaction for post-operative analgesia in pediatric unilateral ilioinguinal surgeries. So it is good alternative to CCB.
\end{abstract}

Keywords: USG guided transversus abdominis plane block, conventional caudal block, paediatric post-operative analgesia

\section{Introduction}

Pain is an unpleasant effect with significant physiological and psychological changes during surgery and post-operative period. Unilateral Ilioinguinal surgery such as inguinal hernia, Hydrocele, Orchidopexy are commonest surgeries performed in pediatric patients. Regional anesthesia and analgesia techniques are used to attenuate the surgical stress response and to decrease parenteral opioid requirement intraoperatively \& to improve the quality of analgesia with fasten rehabilitation and recovery from surgery ${ }^{[1,2]}$ with good patient-parent satisfaction ${ }^{[3,4,5,6,7]}$ postoperatively.

Caudal epidural analgesia is the most common regional technique performed in children ${ }^{[8]}$. It blocks both somatic and visceral pain. It has a low complication rate than neuraxial block but those complications are more serious than those associated with peripheral nerve blocks such as motor blockade in lower limbs and retention of urine.

Recently, the transversus abdominis plane (TAP) block is used as an effective technique to reduce postoperative pain intensity and opioid consumption after lower abdominal surgery ${ }^{[}$,

${ }^{10]}$. USG guided TAP block has added advantages ${ }^{[11]}$.

1. Correct anatomical visualization of site of deposition

2. Maximum deposition of drug at required site

3. Decreased systemic side effects of drug

4. Decreased overall risk of block failure 
With the emergence of new regional anesthetic techniques which have found to be safe and effective, comes the need to compare the efficacy of new technique to the gold standard, particularly if the new technique has lower risk profile.

Primary aim of the study is to evaluate and to compare the analgesic efficacy of Transversus Abdominal Plane (TAP) Block and Caudal Epidural Block (CEB) by means of postoperative duration of analgesia and consumption of total rescue analgesic.

Secondary aim is to compare quality of post-operative pain relief, frequency of need of rescue analgesic within $24 \mathrm{hrs}$, adverse reaction, residual motor block, side effect and complications if any.

\section{Materials and Methods \\ Study Design: Prospective, Randomized, Single blinded study.}

Reference Population: All the paediatric patients aged 01$07 \mathrm{yrs}$ who got admitted to surgery wards for unilateral ilioinguinal surgeries

Sampling Technique: Computer generated random number table Patients were randomly divided into 2 study groups after the induction of General Anaesthesia.

Group T (n=30): Received USG-guided TAP Block with $0.5 \mathrm{ml} / \mathrm{kg}$ of $0.25 \%$ bupivacaine.

Group C $(\mathbf{n}=30)$ : Received Caudal Epidural Block with $1 \mathrm{ml} / \mathrm{kg}$ of $0.25 \%$ bupivacaine

\section{Inclusion criteria}

a) Patients of either sex, aged between 01-07 years.

b) Patients belonging to American Society of Anesthesiologists Grade I \& II.

c) Patient scheduled for unilateral ilioinguinal surgeries.

\section{Exclusion criteria}

a) Patient or Parental refusal for the procedure.

b) Patients with significant coagulopathies and bleeding tendencies

c) Local infection at the block site.

d) Patient allergic to amide local anesthetics.

\section{Anaesthesia Procedure}

Routine pre anesthetic check-up and baseline investigation will be done. Intravenous line will be secured. Intravenous maintance fluid started at $4 \mathrm{ml} / \mathrm{kg} / \mathrm{hr}$ from NBM hrs. Patient will be premedicated with Inj Midazolam $0.03 \mathrm{mg} / \mathrm{kg}$ and Inj Glycopyrolate $0.004 \mathrm{mg} / \mathrm{kg}$ intravenously, $10 \mathrm{~min}$ prior to surgery. Inhalation induction will be done with oxygen, nitrous oxide and $8 \%$ sevoflurane delivered through Jackson Rees modification of Ayre's T piece and face mask, with standard monitoring. Appropriate size LMA will be inserted and anesthesia will be maintained with $50 \%$ oxygen, $50 \%$ nitrous oxide and sevoflurane $2 \%$ with fresh gas flow 2-3 liters/min. After induction of General Anesthesia, child will undergo, either Caudal Block or TAP Block, by computer generated randomization.

\section{Conventional Caudal Block}

A single shot caudal block will be performed with aseptic precautions using $23 \mathrm{G}$ hypodermic needle with $0.25 \%$ bupivacaine $1 \mathrm{ml} / \mathrm{kg}$ by a skilled anesthesiologist or resident under supervision of consultant anesthesiologist.

\section{Tap Block}

Under all aseptic precautions, USG guided unilateral TAP Block performed with the transducer $(6-13 \mathrm{MHz})$ placed in midpoint between the lower costal margin and iliac crest. The layers of External oblique, internal oblique and transverses abdominis muscles are identified just superior to the anterior superior iliac spine. A $22 \mathrm{G}$ short bevelled block needle inserted in-plane with the transducer, in an anterioposterior direction. $0.25 \%$ bupivacaine $0.5 \mathrm{ml} / \mathrm{kg}$ deposited in the space between internal oblique \& transversus abdominis. Correct needle tip placement and deposition of local anaesthetic is indicated by the appearance of a hypoechoic fluid pocket immediately deep to the hyperechoic fascial plane below the internal oblique, and above the transversus abdominis.

Surgery will be allowed to start $15 \mathrm{~min}$ after the study procedures. After completing the surgery, at the beginning of skin closure, Sevoflurane and nitrous oxide will be discontinued. LMA removed and the child will be shifted to recovery room, breathing room air. For post- op analgesia Diclofenac suppository placed PR every 8 hrly.

\section{Data Collection}

HR, MAP, RR and SPO2 recorded before \& after induction and then every 15 min after the block procedure. Patients were monitored for pain relief, duration of analgesia, frequency of need of rescue analgesia, residual motor blockade and complications or side effects if any after 30 min of extubation and 2, 4, 6, 8, 12 and 24 hrs postoperatively.

Post operatively pain was monitored by CHEOPS pain score $\&$ Parent and Patient Satisfaction score and residual motor blockade by Modified Bromage Scale(12) If the CHEOPS pain score will be $\geq 4$ then the patient will receive Paracetamol $15 \mathrm{mg} / \mathrm{kg}$ orally as rescue analgesia. Duration of analgesia is defined as the time from the study procedure to time of consumption of first dose of rescue analgesia

Table 1: CHEOPS pain score (13) (Children's Hospital Eastern Ontario Pain Scale)

\begin{tabular}{|c|c|c|}
\hline Item & Structure & Score \\
\hline \multirow{3}{*}{ Crying } & None & 0 \\
\cline { 2 - 3 } & Moaning/crying & 1 \\
\cline { 2 - 3 } Facial Expression & Screaming & 2 \\
\hline \multirow{3}{*}{ Verbal } & Relaxed/smiling & 0 \\
\cline { 2 - 3 } & Wry mouth & 1 \\
\cline { 2 - 3 } & Grimace (mouth \& eyes) & 2 \\
\cline { 2 - 3 } & Positive Statement & 0 \\
\hline \multirow{3}{*}{ Posture of Legs } & Negative Statement & 1 \\
\cline { 2 - 3 } & Suffering from Pain & 2 \\
\cline { 2 - 3 } & Neutral, released & 0 \\
\hline \multirow{3}{*}{ Torso } & Kicking about/conscious move & 1 \\
\cline { 2 - 3 } & Stretched & 2 \\
\cline { 2 - 3 } & Neutral & 2 \\
\cline { 2 - 3 } & Variable, upright & 1 \\
\hline
\end{tabular}

\section{Parent Patient Satisfaction Score}

The general satisfaction of the children and/or their parents was also considered and recorded post operatively on a 5 
point scale as- completely dissatisfied, dissatisfied and not satisfied, nor dissatisfied, satisfied or completely satisfied.

\section{Modified Bromage Scale ${ }^{[12]}$}

For assessment of Residual motor blockade

Grade 0: No motor block, child moves limbs freely

Grade 1: Inability to flex knees

Grade 2: No movement possible in leg

\section{Inadequate Block}

Intra op increase in HR and MAP by more than $15 \%$ of baseline will be taken as INADEQUATE ANALGESIA and will treat with Inj Fentanyl $0.001 \mathrm{mg} / \mathrm{kg}$ IV.

\section{Failed Block}

If there will be gross body movement even after one of the two study procedure, then it will be considered as failed block and alternative analgesia will be given to the patient. The case will be excluded from study.

\section{Statistical Analysis}

Data was compiled using excel sheet. Parametric data will be reported as mean \pm SD and analyzed with the Unpaired- $t$ test. Nonparametric data will be reported as median and analyzed with Mann-Whitney U-test. Statistical significance was set at 0.05 .

\section{Observations and Results}

Table 2: Demographic Variables

\begin{tabular}{|c|c|c|c|c|}
\hline Sr. No & Characteristic & Group T & Group C & P value \\
\hline 1. & Age (yrs) & $4.40 \pm 1.831($ Mean \pm SD) & $4.37 \pm 1.650($ Mean \pm SD) & 0.941 \\
\hline 2. & Weight $(\mathrm{kg})$ & $13.73 \pm 3.667$ (Mean \pm SD) & $13.40 \pm 4.090($ Mean \pm SD) & 0.741 \\
\hline 3. & Sex-Male & 27 & 28 & 0.640 \\
\hline & Female & 3 & 2 & 0.721 \\
\hline 4. & ASA I & 24 & 25 & 0.744 \\
\hline 5. & ASA II & 6 & 5 & 0.732 \\
\hline
\end{tabular}

Demographic Variable such as Age, Sex, and Weight \& ASA class were comparable in both the groups $(P$ value $>0.05)$. Mean duration of surgery and mean duration of anaesthesia were comparable in both the groups. $(P$ value $>0.05)$

Table 3: Surgical Data

\begin{tabular}{|c|c|c|c|}
\hline Parameter & Group T (Mean \pm SD) & Group C (Mean \pm SD) & P Value \\
\hline Duration of surgery (MIN) & $76.00 \pm 9.29$ & $76.60 \pm 8.62$ & 0.796 \\
\hline Duration of anesthesia (NEN) & $99.30 \pm 9.11$ & $100.03=8.01$ & 0.741 \\
\hline
\end{tabular}

Mean duration of surgery and mean duration of anaesthesia were comparable in both the groups. $(P$ value $>0.05)$

Table 4: Intra-operative variations in mean heart rate

\begin{tabular}{|c|c|c|}
\hline Mean HR (Beats/min) & Group T (Mean+ SD) & Group C (Mean+SD) \\
\hline Baseline & $104.27 \pm 8.18$ & $104.60 \pm 7.92$ \\
\hline $0 \mathrm{~min}$ & $97.67 \pm 7.88$ & $97.50 \pm 8.03$ \\
\hline $15 \mathrm{~min}$ & $101.40 \pm 7.97$ & $100.87 \pm 8.64$ \\
\hline $30 \mathrm{~min}$ & $95.73 \pm 7.20$ & $>0.05$ \\
\hline $45 \mathrm{~min}$ & $92.87 \pm 7.55$ & $>05.50 \pm 7.44$ \\
\hline $60 \mathrm{~min}$ & $90.40 \pm 6.98$ & $92.70 \pm 7.69$ \\
\hline $75 \mathrm{~min}$ & $90.07 \pm 6.73$ & $89.93 \pm 7.17$ \\
\hline $90 \mathrm{~min}$ & $89.12 \pm 6.06$ & $89.45 \pm 7.32$ \\
\hline
\end{tabular}

Change in mean heart rate and mean arterial pressure from baseline was comparable in both the groups during the intra- operative period. The difference was statistically not significant. $(P$ Value $>0.05)$

Table 5: Intra-operative variations in mean arterial pressure

\begin{tabular}{|c|c|c|c|}
\hline Mean HR (Mean+SD) & Group T (Mean+ SD) & Group C & P value \\
\hline Baseline & $71.73 \pm 4.33$ & $71.97 \pm 4.46$ & $>0.05$ \\
\hline $0 \mathrm{~min}$ & $67.07 \pm 4.43$ & $66.83 \pm 4.37$ & $>0.05$ \\
\hline $15 \mathrm{~min}$ & $69.27 \pm 4.16$ & $69.07 \pm 4.50$ & $>0.05$ \\
\hline $30 \mathrm{~min}$ & $66.33 \pm 4.16$ & $66.17 \pm 4.50$ & $>0.05$ \\
\hline $45 \mathrm{~min}$ & $65.03 \pm 4.11$ & $65.63 \pm 4.06$ & $>0.05$ \\
\hline $60 \mathrm{~min}$ & $65.03 \pm 4.19$ & $64.53 \pm 4.16$ & $>0.05$ \\
\hline $75 \mathrm{~min}$ & $65.28 \pm 4.18$ & $64.69 \pm 4.12$ & $>0.05$ \\
\hline $90 \mathrm{~min}$ & $65.92 \pm 3.77$ & $65.50 \pm 3.79$ & $>0.05$ \\
\hline
\end{tabular}

Table 6: Mean duration of postoperative analgesia

\begin{tabular}{|c|c|c|c|c|}
\hline S. No & Characteristic & Group T (Mean \pm SD) & Group C (Mean \pm SD) & P value \\
\hline 1 & Duration of Post op Analgesia (Mins) & $441.47 \pm 62.50$ & $439.87 \pm 72.04$ & 0.56 \\
\hline
\end{tabular}

Mean duration of Post-operative analgesia was comparable in both groups. The difference was found to be statistically not significant. $(P$ Value $>0.05)$. 


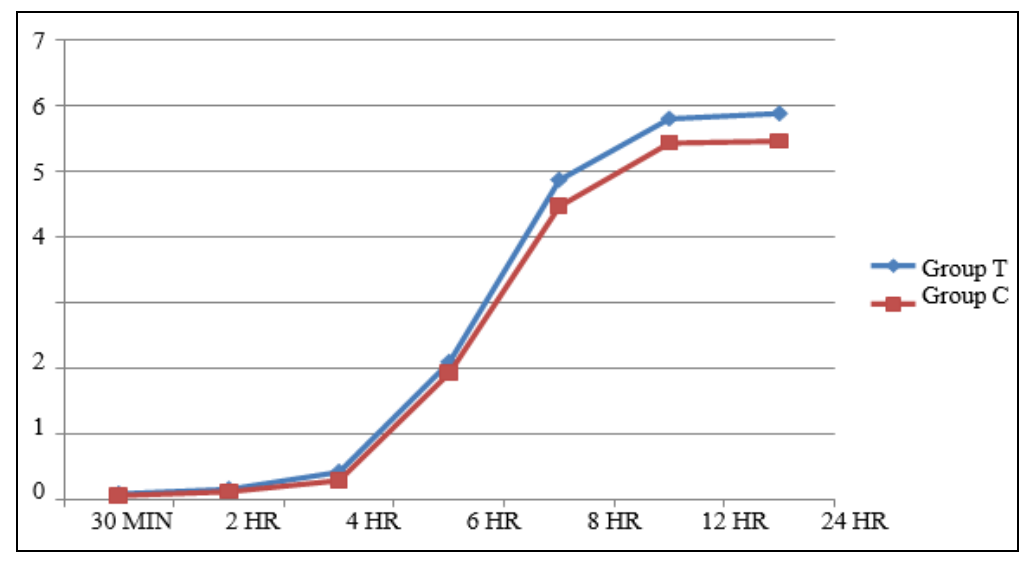

Fig 1: Mean Cheops pain score post-operatively till $24 \mathrm{hrs}$

Pain scores were similar in both the groups. The difference was found to be statistically non-significant. $(P$ Value $>0.05)$

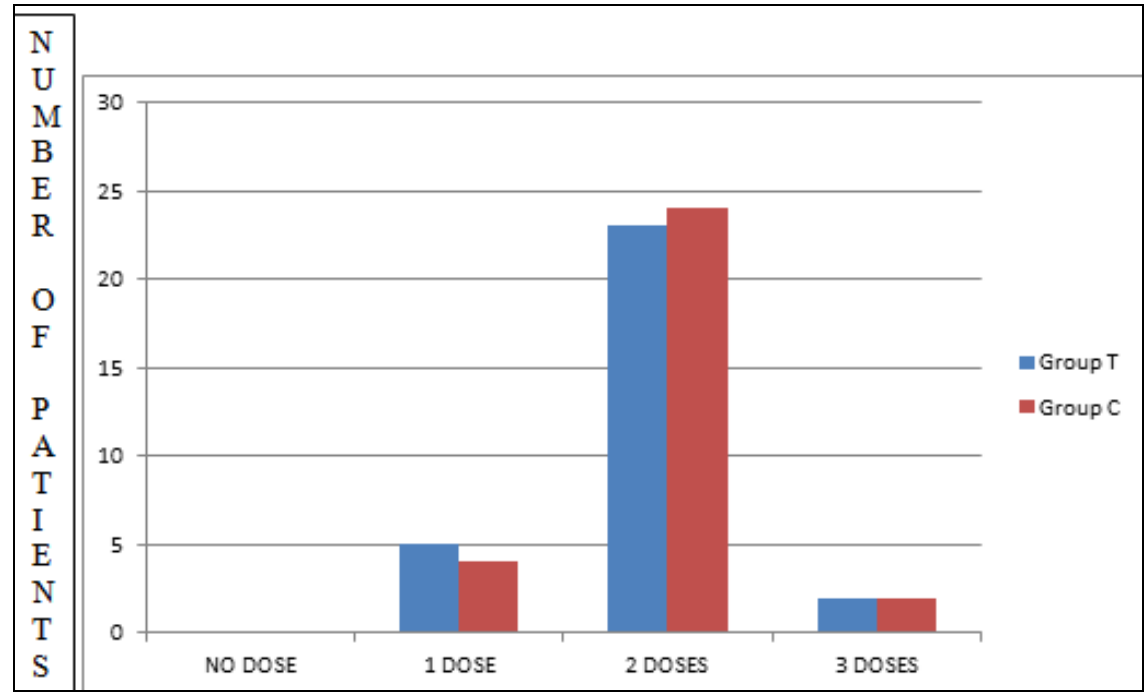

Fig 2: Number of doses rescue of analgesia in the first $24 \mathrm{hrs}$ of post-operative period

The difference was found to be statistically not significant. $(P$ Value $>0.05)$

\section{Patient parent satisfaction score}

As far as Patient Parent Satisfaction Score was concerned,
24 patients in Group $\mathrm{T}$ were completely satisfied than 19 patients in Group C. None of the patient was completely dissatisfied in Group $\mathrm{T}$ whereas 1 patient of Group $\mathrm{C}$ was completely dissatisfied. The difference was found to be statistically significant.

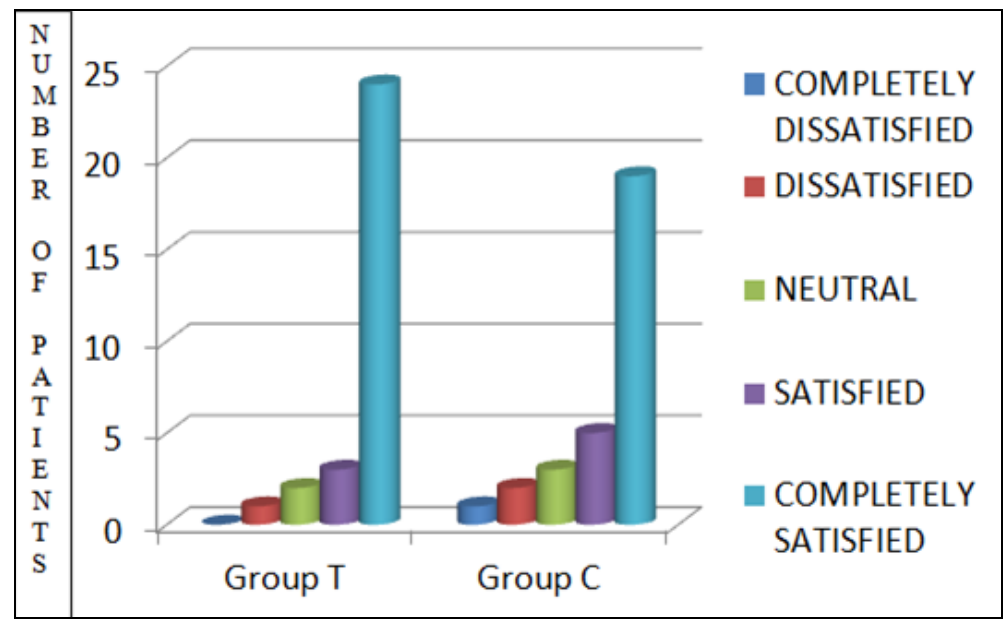

Fig 3: 24 patients in Group T were completely satisfied than 19 patients in Group C $(P$ Value $<0.05)$

\section{Side effect}

Residual motor block was present only in patients of Group C. There was no residual motor block present in patients of
Group T. The difference was found to be statistically significant $(P$ Value $<0.05)$

There were no other clinically significant complications 
noted in both the groups either intra-operatively or postoperatively in the form of injury to underlying structures, hematoma formation, infection, urinary retention or respiratory depression.

\section{Discussion}

USG guided TAP block suggest equivalent block qualities with increased safety. Compared with Group TAPB, the Group CCB had higher incidence of residual motor block. No side effects or complications were noted in both the groups.

In the study done by Joseph et al., $2008^{[14]}$ it was found the TAP block provided effective analgesia following subumblical and lower abdominal procedures in infants and children when compared with the usual practice of caudal analgesia. This was in agreement with this present study.

Bryskitn Robert et al. performed Double-blinded randomized controlled trial of TAPB versus CEB for Lower Abdominal Surgery in Children and concluded that there was no statistical difference in post-op analgesic requirement in first 8 hours; however at 24 hours patients who received TAP block required less cumulative analgesic than caudal group ${ }^{[15]}$. This result was consistent in our study as analgesics requirement in both group was almost same till 4-5hrs; later group with TAPB required less analgesics.

Wafaa Mohamed Alsadek et al. conducted study to compare USG guided TAP block and USG guided Caudal block for pain relief in children undergoing lower abdominal surgeries states that there was no significant difference between two groups regarding hemodynamics; post-op analgesic requirements were higher in group with Caudal Block compared to group with TAP block; PatientParent Satisfaction score was more in TAP block group than Caudal block group ${ }^{[16]}$. This result was consistent in our study

\section{Conclusion}

- USG guided TAP block is safe and effective method with better impact on pain score \& good Parent Patient satisfaction compared to $\mathrm{CCB}$ in pediatric patients posted for unilateral ilioinguinal surgeries.

- So TAP Block can be considered as an alternative to $\mathrm{CCB}$ in day care surgeries.

\section{References}

1. Kehlet H. Surgical stress: the role of pain and analgesia. Br J Anaesth. 1989; 63:189-95.

2. Capdevila X, Barthelet Y, Biboulet P et al. Effects of perioperative analgesic technique on the surgical outcome and duration of rehabilitation after major knee surgery. Anesthesiology. 1999; 91:8-15.

3. White PF, Kehlet $\mathrm{H}$. Improving postoperative pain management. Anesthesiology. 2010; 112:220-5.

4. Perkins FM, Kehlet H. Chronic pain as an outcome of surgery. Anesthesiology. 2000; 93:1123-33.

5. Bay-Nielsen M, Perkins FM, Kehlet H. Pain and functional impairment 1 year after inguinal herniorrhaphy: a nationwide questionnaire study. Ann Surg. 2001; 233:1-7.

6. Poobalan AS, Bruse J, Smith WC, King PM, Krulowski $\mathrm{ZH}$, Chambers WA. A review of chronic pain after inguinal herniorrhaphy. Clin J Pain. 2003; 19:48-54.
7. Ong CKF, Lirk P, Seymour RA, Jenkins BJ. The efficacy of preemptive analgesia for acute postoperative pain management: a meta-analysis. Anesth Analg. 2005; 100:757-73.

8. Miller R. Miller's Anesthesia. 7th ed. Philadelphia, Pa: Elsevier, Churchill Livingstone, 2532-2533.

9. McDonnell JG, O’Donnell B, Curley G, Heffernam A, Power C, Laffey JG. The analgesic efficacy of transversus abdominis plane block after abdominal surgery: a prospective randomized controlled trial. Anesth Analg. 2007; 104:193.

10. McDonnell JG, O'Donnell B, Farrel $\mathrm{T}$ et al. Transversus abdominis plane block: a cadaveric and radiological evaluation. Reg Anesth Pain Med 2007; 32:399-404.

11. Marhofer P, Sitzwohl C, Greher M, Kapral S. Ultrasound guidance for infraclavicular brachial plexus anesthesia in children. Anesthesia. 2004; 59:642-646.

12. Mert Akbas, Halide Akbas, Arif yegin. Comparison of effect of clonidine and ketamine added to ropivacaine on stress hormone level and the duration of caudal analgesia. Paediatric anaesthesia. 2005; 15:580-585.

13. Wafaa Mohamed Alsadek, Manal Mohamed Al-Gohari et al. Ultrasound guided TAP Block versus Ultrasound guided Caudal block for pain relief in children undergoing lower abdominal surgeries. Egyptian Journal of Anesthesia-received 6 July 2014; revised 18; accepted. 2015; 31:155-160.

14. Joseph D Tobias. Preliminary experience with transversus abdominis plane block for postoperative pain relief in infants and children. Saudi Journal of Anesthesia. 2009; 3(1):1-6.

15. Bryskin, Robert B. MD-Anesthesia \& Anesthesia. 2015; 121(2):471-478.

16. Wafaa Mohamed Alsadek-Egyptian Journal of Anesthesia-received 6 July 2014; revised; accepted, 2015. 